\title{
Novel strategies in newborn screening for cystic fibrosis: a prospective controlled study
}

\author{
Annette M M Vernooij-van Langen, ${ }^{1} \mathrm{~J}$ Gerard Loeber, ${ }^{2}$ Bert Elvers, ${ }^{2}$ Ralf H Triepels, ${ }^{3}$ \\ Johan J P Gille, ${ }^{4}$ Catharina P B Van der Ploeg, ${ }^{5}$ Sandra Reijntjens, ${ }^{1}$ \\ Edward Dompeling, ${ }^{6}$ Jeannette E Dankert-Roelse, ${ }^{7}$ on behalf of the CHOPIN Study \\ Group
}

\section{See Editorial, p 281 \\ - An additional material is published online only. To view this file please visit the journa online (http://thorax.bmj.com/ content/67/4.toc)}

${ }^{1}$ Department of Research and Innovation, Atrium Medical Centre, Heerlen, The

Netherlands

${ }^{2}$ Laboratory for Infectious

Diseases and Perinatal

Screening, National institute for Public Health and the

Environment (RIVM), Bilthoven, The Netherlands

${ }^{3}$ Clinical Chemistry Laboratory, St Elisabeth Hospital, Tilburg.

The Netherlands

${ }^{4}$ Department of Clinical

Genetics, VU Medical Centre,

Amsterdam, The Netherlands

${ }^{5}$ Department Public Health and

Prevention, TNO Quality of Life, Leiden, The Netherlands

${ }^{6}$ Department of Paediatric

Pulmonology, Maastricht

University Medical Centre,

Maastricht, The Netherlands

${ }^{7}$ Department of Paediatrics,

Atrium Medical Centre, Heerlen,

The Netherlands

\section{Correspondence to}

Dr Annette M M Vernooii-van Langen, RIVM-LIS, P.O. Box 1 ,

3720 BA Bilthoven, The

Netherlands; amm.vernooij

+chopin@gmail.com

For author footnote see end of the article.

Received 23 August 2011

Accepted 6 December 2011

Published Online First

23 January 2012

\section{ABSTRACT \\ Context Newborn screening for cystic fibrosis (CF) is included in many routine programmes but current strategies have considerable drawbacks, such as false- positive tests, equivocal diagnosis and detection of carriers. \\ Objective To assess the test performance of two newborn screening strategies for CF.}

Design, setting and participants In 2008 and 2009, CF screening was added to the routine screening programme as a prospective study in part of the Netherlands.

Interventions Two strategies were performed in all newborns. In the first strategy, concentrations of immunoreactive trypsinogen (IRT) and pancreatitisassociated protein (PAP) were measured. In the second method, samples with IRT $\geq 60 \mu \mathrm{g} /$ litre were analysed for 36 CFTR mutations, followed by sequencing when a single mutation was detected. Tests were positive only with two identified CFTR mutations.

Main outcome Sensitivity, specificity and positive predictive value (PPV) of both screening strategies. Results 145499 infants were screened. The IRT/PAP approach showed a sensitivity of $95.0 \%$, a specificity of $99.897 \%$ and a PPV of $12.3 \%$. Test properties for the IRT/ DNA/sequencing strategy were respectively $100 \%$, $100 \%$ and $64.9 \%$. Combining both strategies (IRT/PAP/ DNA/sequencing) led to a sensitivity of $95.0 \%$, a specificity of $100 \%$ and a PPV of $87.5 \%$.

Conclusion In conclusion, all strategies performed well. Although there was no statistically significant difference in test performance, the IRT/DNA/sequencing strategy detected one infant that was missed by IRT/PAP (/DNA/ sequencing). IRT/PAP may be the optimal choice if the use of DNA technology must be avoided. If identification of carriers and equivocal diagnosis is considered an important disadvantage, IRT/PAP/DNA/sequencing may be the best choice.

\section{INTRODUCTION}

Newborn screening (NBS) for cystic fibrosis (CF) is widely accepted, but there is no universally accepted screening strategy. ${ }^{1}$ A survey of screening programmes in Europe described 26 different screening strategies. $^{2}$

All programmes start by measuring the concentration of immunoreactive trypsinogen (IRT) in dried blood spots. The second tier is either a limited

\section{Key messages}

What is the key question?

- Newborn screening programmes for cystic fibrosis have considerable drawbacks, such as false-positive tests, equivocal diagnosis and detection of carriers. This study investigated three novel screening strategies.

What is the bottom line?

- A screening strategy consisting of immunoreactive trypsinogen and pancreatitis-associated protein, DNA and sequencing has the best test performances and less carrier detection and equivocal diagnosis than other programmes.

\section{Why read on?}

- We show the results of three screening programmes for cystic fibrosis, the test performances, number of carriers detected and equivocal diagnosis.

CFTR mutation analysis or a repeat measurement of the IRT concentration at the age of 4-6 weeks. ${ }^{3}$ Protocols using IRT alone or IRT/IRT have a high false-positive rate. ${ }^{4}$ The major drawback of using CFTR mutation analysis is the high number of identified healthy carriers and cases with an equivocal diagnosis. ${ }^{15}$

In 2005, pancreatitis-associated protein (PAP) was described as a possible second tier in NBS for CF. Measurement of IRT as well as PAP in dried blood spots may lead to a specific and sensitive screening programme. ${ }^{5}$ A different IRT/PAP protocol was used in Germany in 2009; that is, a 99th percentile IRT cut-off level and a PAP cut-off level of $1.6 \mu \mathrm{g} / \mathrm{l}^{7}$

Screening with IRT/DNA followed by sequencing of the CFTR gene in all samples with only one CFTR mutation may be an alternative strategy. In this approach the screening test is only positive when two mutations are identified. ${ }^{8}$ In California a comparable screening protocol has been in use since 2007, but infants with a single mutation are also referred for a sweat test. ${ }^{9}$

We hypothesised that these two novel screening strategies (IRT/PAP and IRT/DNA/sequencing) may lead to a similar sensitivity to current NBS strategies, but with a higher specificity, less carrier 
detection and less equivocal diagnoses. The study aim was to compare the test performance of these two strategies in a large population of newborns in the Netherlands.

\section{METHODS}

\section{Study population}

In the Netherlands all newborns are included in the routine NBS programme, unless the parents refuse participation (opting-out procedure). The Dutch NBS programme consists of 17 diseases (congenital adrenal hyperplasia, congenital hypothyroid disease, sickle cell disease and 14 metabolic diseases; http://www.rivm. $\mathrm{nl} /$ hielprik). Five laboratories spread over the country perform NBS, and receive heel prick samples from five designated areas. Two laboratories, the reference laboratory (RIVM) and the laboratory of the region South East (Clinical Chemical Laboratory, St Elisabeth Hospital, Tilburg) participated in the study.

All heel prick samples received in the two participating laboratories were tested with both screening strategies in 2008 and 2009, unless the parents refused the screening for CF. Parents were informed about the screening for CF by a leaflet, available in 10 languages.

\section{Screening protocols}

Figure 1 shows a flow chart of both screening strategies. The IRT/PAP protocol consisted of measurement of IRT and PAP in all samples. A positive result was defined as a combination of IRT $\geq 100 \mu \mathrm{g} /$ litre and PAP $\geq 1.6 \mu \mathrm{g} /$ litre or IRT $\geq 60 \mu \mathrm{g} /$ litre and PAP $\geq 3.0 \mu \mathrm{g} /$ litre, as described before, ${ }^{6}$ and corrected according to the publication at http://www.isns-neoscreening.org/htm/ news in March 2011. In the IRT/DNA/sequencing protocol, an elevated IRT $(\geq 60 \mu \mathrm{g} / \mathrm{l})$ was followed by a DNA mutation analysis consisting of 36 mutations. When only one mutation was detected, DNA sequencing was performed. In this strategy the screening test was positive when two mutations were detected. All newborns with a positive screening result with one or both strategies were referred to a CF centre for a sweat test to confirm or to exclude the diagnosis.

\section{Definitions}

The diagnosis of CF was confirmed by a sweat chloride concentration of $\geq 60 \mathrm{mmol} /$ litre. If this was not possible or the sweat test failed, the diagnosis can also be confirmed by two CFTR mutations, and/or a meconium ileus and/or positive family history. ${ }^{10} 11$

An equivocal diagnosis was defined according to international standards as an equivocal sweat test result (chloride 30-60 mmol/litre) or a normal sweat test result (chloride $<30 \mathrm{mmol} /$ litre) on two occasions in a newborn with two CFTR mutations of which one or both have unclear clinical consequences. ${ }^{11}$ All infants with an equivocal diagnosis were regularly seen at the $\mathrm{CF}$ centres during the first year of life. For the IRT/PAP strategy, CF was excluded when the chloride concentration was below $30 \mathrm{mmol} /$ litre. For the IRT/DNA/ sequencing strategy newborns with a single CFTR mutation after DNA sequencing were considered as healthy carriers and screen negative.

\section{Laboratory techniques}

The AutoDELFIA Neonatal IRT (B005-112, Perkin-Elmer, Turku, Finland) was used for determination of IRT, according to the manufacturer's protocol.

For measuring PAP, the MucoPAP ELISA (DynaBio, Marseille, France) was modified to a DELFIA method following a protocol of PerkinElmer. This is a time-resolved fluoroimmunoassay, based on a biotinylated anti-PAP antibody and a $100 \mu \mathrm{l} \mathrm{Eu-}$ Streptavidin tracer. The minimal detectable value of the PAP assay was $0.1 \mu \mathrm{g} /$ litre and the maximal value $15.8 \mu \mathrm{g} /$ litre.

DNA was extracted from dried blood spots using the EZ1 DNA tissue kit on a Biorobot EZ1 (Qiagen, Valencia, California, USA). Mutation analysis of the CFTR gene was performed by screening for 35 CFTR mutations with the Line Probe Assay of Innogenetics (INNO-LiPA CFTR19 and INNO-LiPA CFTR17 +Tn) (Innogenetics, Gent, Belgium) or by DNA sequence analysis of all coding exons of the CFTR gene (including intron/ exon boundaries) using standard procedures. Newborns with two CFTR mutations or one CFTR mutation and one variant with unknown clinical significance were referred. Polymorphisms and variants known to cause only male infertility were considered non disease causing and ignored.

Sweat tests were performed by the Gibson-Cooke Quantitative Pilocarpin Iontophoresis or the Macroduct method according to international guidelines. ${ }^{12}$
Figure 1 Flowcharts of both screening strategies: immunoreactive trypsinogen (IRT)/pancreatitisassociated protein (PAP) and IRT/DNA/ sequencing. CF, cystic fibrosis.

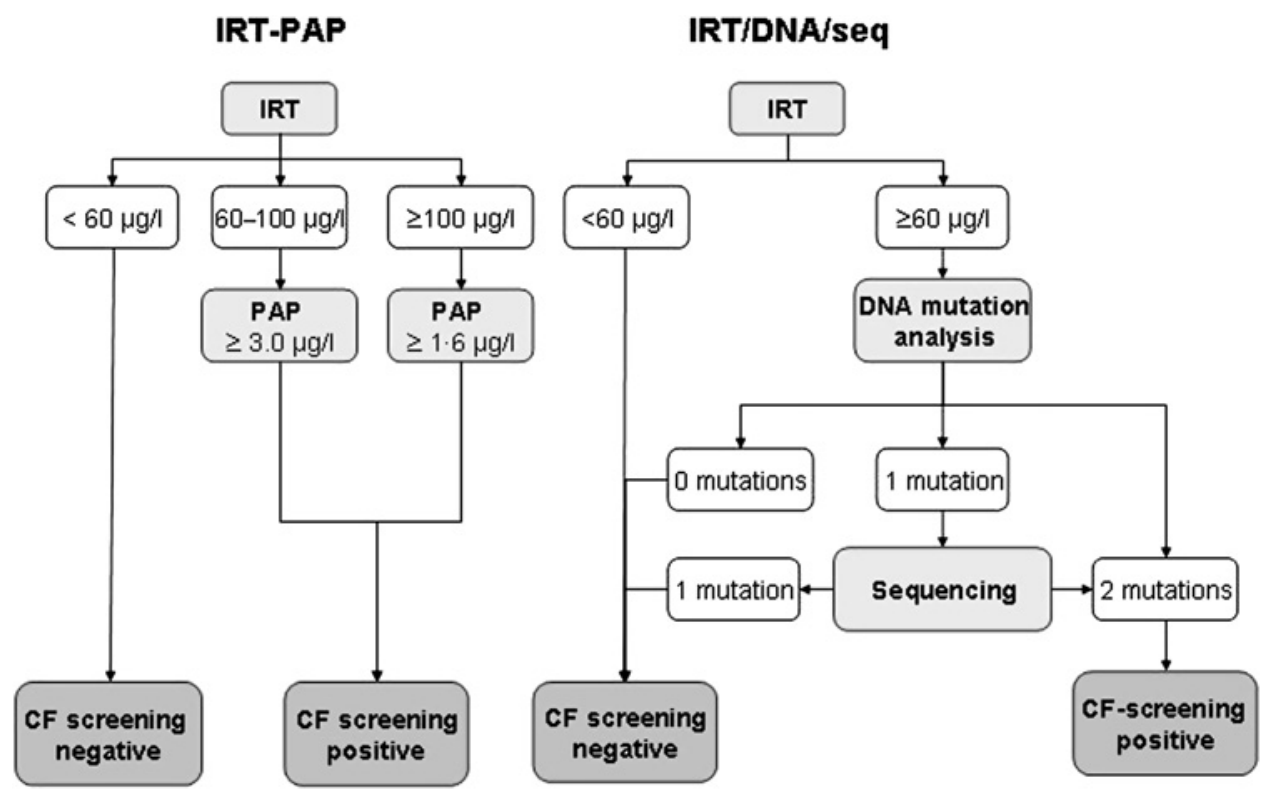




\section{The Dutch Pediatric Surveillance Unit}

Paediatricians in the Netherlands reported all children with a new diagnosis of CF to the Dutch Paediatric Surveillance Unit (DPSU). This registration started in July 2007 and is still running. The main goal of the registration is to find infants missed by NBS.

\section{Retrospective analysis}

When parents gave permission, we performed a retrospective analysis using both screening protocols in heel prick cards of children reported to have CF at the DPSU and those from the four participating CF centres born since 2003.

\section{Statistical analysis}

We determined the test characteristics (with 95\% CIs) of the two screening protocols (sensitivity, specificity and positive predictive value (PPV)). For determination of the sensitivity, newborns with a meconium ileus were excluded from the analysis. ${ }^{13}$

A power analysis was made for both specificity and sensitivity. For both strategies a cohort of 80000 newborns would be sufficient to show that the specificity will be higher than $99.64 \%$ with a power of $80 \%$. Assuming a sensitivity of $95 \%$ a total number of 62 infants with CF will lead to an estimated $95 \%$ CI between $85 \%$ and $99 \%$. To achieve a reliable estimate of the sensitivity a cohort of children known to have CF was added to the study for a retrospective analysis.

We compared the test performances of the two strategies using a McNemar's test. $p$ Values $<0.05$ were considered statistically significant.

A post hoc analysis was done for a combined IRT/PAP/DNA/ sequencing strategy using the data of both strategies. Statistical analysis was carried out using SPSS V.17.0 software.

\section{RESULTS}

In 2008 and 2009, 145499 newborns were screened for CF; 72874 in 2008 and 72625 in 2009. A total number of 372713 newborns were born alive in the Netherlands in both years; the study region counted for $39 \%$ of all births.

\section{IRT/PAP strategy}

Results of the IRT/PAP strategy are shown in figure $2 \mathrm{~A}$ and tables 1 and 2. A total of 171 (0.12\%) newborns were referred for a sweat test. CF was confirmed in 19 newborns. One infant was missed because of a low PAP concentration $(0.8 \mu \mathrm{g} /$ litre $)$; this infant had two mutations (F508del and A455E) and a positive sweat test (chloride $65 \mathrm{mmol} /$ litre).

Six infants had an equivocal sweat test result (chloride concentration $30-51 \mathrm{mmol} / \mathrm{litre}$ ); two of these infants were diagnosed with CF by two mutations (F508del and F508del); one of them had an abnormal repeat sweat test $(69 \mathrm{mmol} / \mathrm{litre})$. One infant had a normal repeat sweat test and no mutations. In three infants a follow-up sweat test was not performed by the paediatric pulmonologist because the DNA results showed no mutations.

IRT and PAP concentrations for the whole population are presented in figure 3.

\section{IRT/DNA/sequencing strategy}

The results are presented in figure $2 \mathrm{~B}$ and tables 1 and 2.This strategy revealed 20 infants with CF, 13 infants with an equivocal diagnosis and 67 carriers, and had a referral rate of $0.026 \%$. The PPV of this strategy was $64.9 \%$ because infants with an equivocal diagnosis cannot be considered to have CF.

IRT/PAP and IRT/DNA/sequencing identified the same 19 patients, whereas the second strategy detected one more patient. Although the IRT/DNA/sequencing strategy was better for sensitivity, specificity and PPV (McNemar; $\mathrm{p}=1.00)$ the differences were not significant. The prevalence of CF in the study region was 1:6062.

\section{IRT/PAP/DNA/sequencing strategy}

A post hoc analysis was performed for the IRT/PAP/DNA/ sequencing strategy. In this strategy a DNA mutation analysis

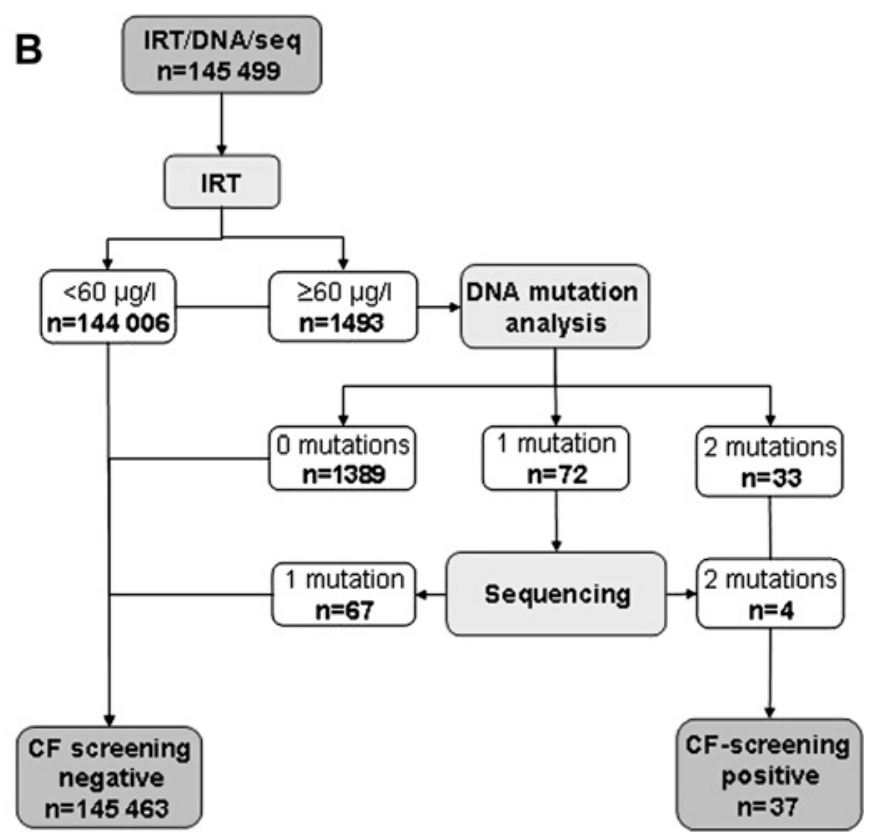

Figure 2 (A) Results of the immunoreactive trypsinogen (IRT)/pancreatitis-associated protein (PAP) screening strategy. (B) Results of the IRT/DNA/ sequencing screening strategy (2008 and 2009). CF, cystic fibrosis. 
Table 1 Results of three different screening strategies with an immunoreactive trypsinogen cut-off level of $60 \mu \mathrm{g} / \mathrm{l}(\mathrm{n}=145499)$

\begin{tabular}{llll}
\hline & IRT/PAP & IRT/DNA/seq & IRT/PAP/DNA/seq \\
\hline Test positive, n (\%) & $171(0.12)$ & $37(0.025)$ & 24 (0.016) \\
CF with MI* & 2 & 4 & 2 \\
CF, no MI & 19 & 20 & 19 \\
False positive & 146 & 0 & 0 \\
Equivocal diagnosis† & 4 & 13 & 3 \\
Test negative & 145328 & 145462 & 145475 \\
No CF & 145325 & 145462 & 145472 \\
CF with MI* & 2 & 0 & 2 \\
CF, no MI & 1 & 0 & 1 \\
Carriers & 0 & 67 & 8 \\
Sensitivity, \% (95\% Cl) & 95.0 (73.1 to 99.7) & 100 (80.0 to 100) & 95.0 (73.1 to 99.7) \\
Specificity, \% (95\% Cl) & 99.897 (99.879 to 99.912) & 99.991 (99.984 to 99.995) & 99.998 (99.993 to 100) \\
PPV, \% (95\% Cl) & 12.3 (7.9 to 8.4) & 64.9 (47.4 to 79.3) & 87.5 (66.5 to 96.7) \\
\hline
\end{tabular}

*Excluded from the analysis.

†Infants with an equivocal sweat test result and/or a second mutation associated with an unclear phenotype and a normal or equivocal sweat test (=false-positive screening test result).

$\mathrm{CF}$, cystic fibrosis; IRT, immunoreactive trypsinogen; MI, meconium ileus; PAP, pancreatitis-associated protein; PPV, positive predictive value; seq, sequencing CFTR gene.

would be done in all samples with a positive IRT/PAP result, followed by sequencing when a single mutation was found. The results are presented in figure 4 and table 1 . With this screening strategy the same 19 patients as in the IRT/PAP strategy would have been found, three infants with an equivocal diagnosis and eight carriers.

\section{Diagnosis}

Sweat tests were performed between 3 and 4 weeks after birth. A total of 175 sweat tests were performed of which 145

Table 2 Immunoreactive trypsinogen and pancreatitis-associated protein concentrations, CFTR gene mutation analysis and sweat tests in infants with cystic fibrosis detected by newborn screening

\begin{tabular}{|c|c|c|c|c|c|}
\hline & $\begin{array}{l}\text { IRT } \\
\text { ( } \mu \mathrm{g} / \text { /itre) }\end{array}$ & $\begin{array}{l}\text { PAP } \\
(\mu \mathrm{g} / \text { /itre })\end{array}$ & Mutation 1 & Mutation 2 & $\begin{array}{l}\text { Sweat test chloride } \\
\text { (mmol/litre) }\end{array}$ \\
\hline 1 & 438 & 5.3 & F508del & F508del & 74 \\
\hline 2 & 284 & 1.8 & F508del & F508del & 88 \\
\hline 3 & 266 & 9.8 & F508del & F508del & 97 \\
\hline 4 & 237 & 1.8 & F508del & F508del & 11 and 74 \\
\hline 5 & 197 & 4.3 & F508del & F508del & 69 \\
\hline $6^{*}$ & 191 & 12.6 & F508del & C.3889dupT & 94 \\
\hline 7 & 164 & 14.4 & F508del & G542X & 102 \\
\hline 8 & 129 & 4.3 & F508del & F508del & Failed \\
\hline 9 & 110 & 2.2 & F508del & F508del & 94 \\
\hline 10 & 109 & 2.0 & F508del & F508del & 51 \\
\hline 11 & 105 & 4.4 & F508del & F508del & 149 \\
\hline 12 & 155 & 2.6 & F508del & F508del & 111 \\
\hline 13 & 191 & 12.6 & F508del & F508del & 4 \\
\hline 14 & 116 & 15.8 & F508del & F508del & Failed 3 times \\
\hline 15 & 293 & 5.7 & F508del & $2184 A$ & 120 \\
\hline $16^{*}$ & 228 & 15.8 & F508del & 1294_1300del & 99 \\
\hline 17 & 218 & 4.5 & F508del & G85E & 99 \\
\hline 18 & 153 & 4.0 & F508del & S1251N & 77 \\
\hline $19^{*}$ & 141 & 15.8 & F508del & E730X & 82 \\
\hline $20 \neq$ & 78 & 0.8 & F508del & A455E & 65 \\
\hline $21 \dagger$ & 114 & 11.2 & F508del & F508del & Failed \\
\hline $22 \dagger$ & 109 & 0.8 & F508del & F508del & 78 \\
\hline $23 \dagger$ & 93 & 1.3 & F508del & F508del & - \\
\hline $24 \dagger$ & 75 & 6.7 & F508del & F508del & 78 \\
\hline
\end{tabular}

*Second mutation detected by sequencing.

tInfants with meconium ileus (no. 21-24) were excluded from the analysis.

†This infant was missed with IRT/PAP but detected with IRT/DNA/sequencing.

$\mathrm{CF}$, cystic fibrosis; IRT, immunoreactive trypsinogen; PAP, pancreatitis-associated protein. succeeded (83\%). In five infants no sweat test was done because of a congenital lethal condition ( $\mathrm{n}=3$; cardiomyopathy, multiple congenital anomalies and trisomy 18), refusal of the parents ( $\mathrm{n}=1$; no mutations after DNA analysis), a premature infant of 25 weeks ( $n=1$; the DNA analysis was repeated instead of the sweat test).

The sweat test confirmed the diagnosis of CF in 17 infants. The test failed in two infants but their diagnosis could be based on two mutations (F508del and F508del) and clinical symptoms (ileum atresia and meconium plug respectively). One infant had an equivocal sweat test result but was diagnosed because of two mutations (F508del and F508del).

The IRT/DNA/sequencing strategy revealed 13 infants with an equivocal diagnosis, all of whom had two mutations identified, with one of the two being of unclear clinical significance. Three of these infants had equivocal sweat test results (chloride 33, 34, $36 \mathrm{mmol} /$ litre; all had R117H-7T as a second mutation), the other 10 had normal sweat tests (F508del/394delTT/ S1251N/R553X combined with R117H-7T n=8, F508del/L967S, F508del/O1352H) (table 3).

\section{Time to diagnosis}

Median times between heel prick and screening test result and between screening test result and diagnosis are shown in table 4 .

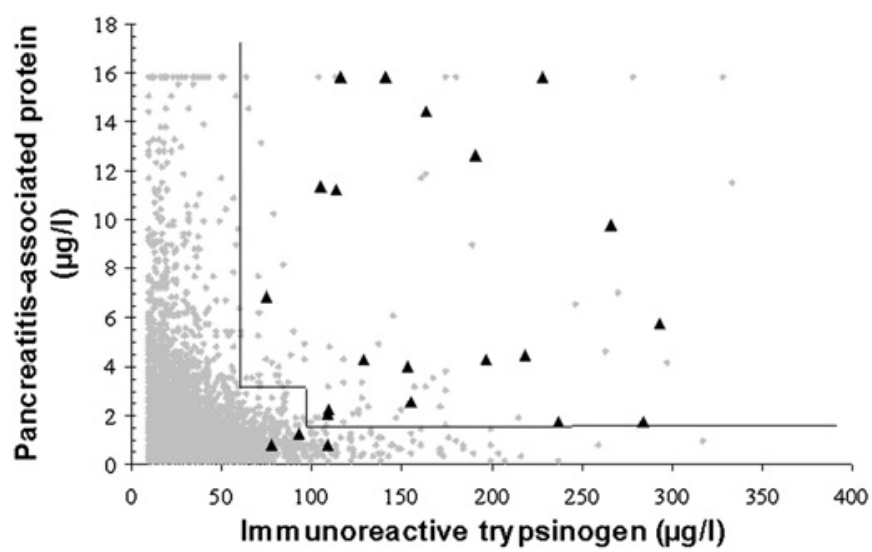

Figure 3 Correlation between immunoreactive trypsinogen and pancreatitis-associated protein concentrations in heel prick blood. 
Figure 4 Adjusted cut-off levels. CF, cystic fibrosis; IRT, immunoreactive trypsinogen; PAP, pancreatitisassociated protein.

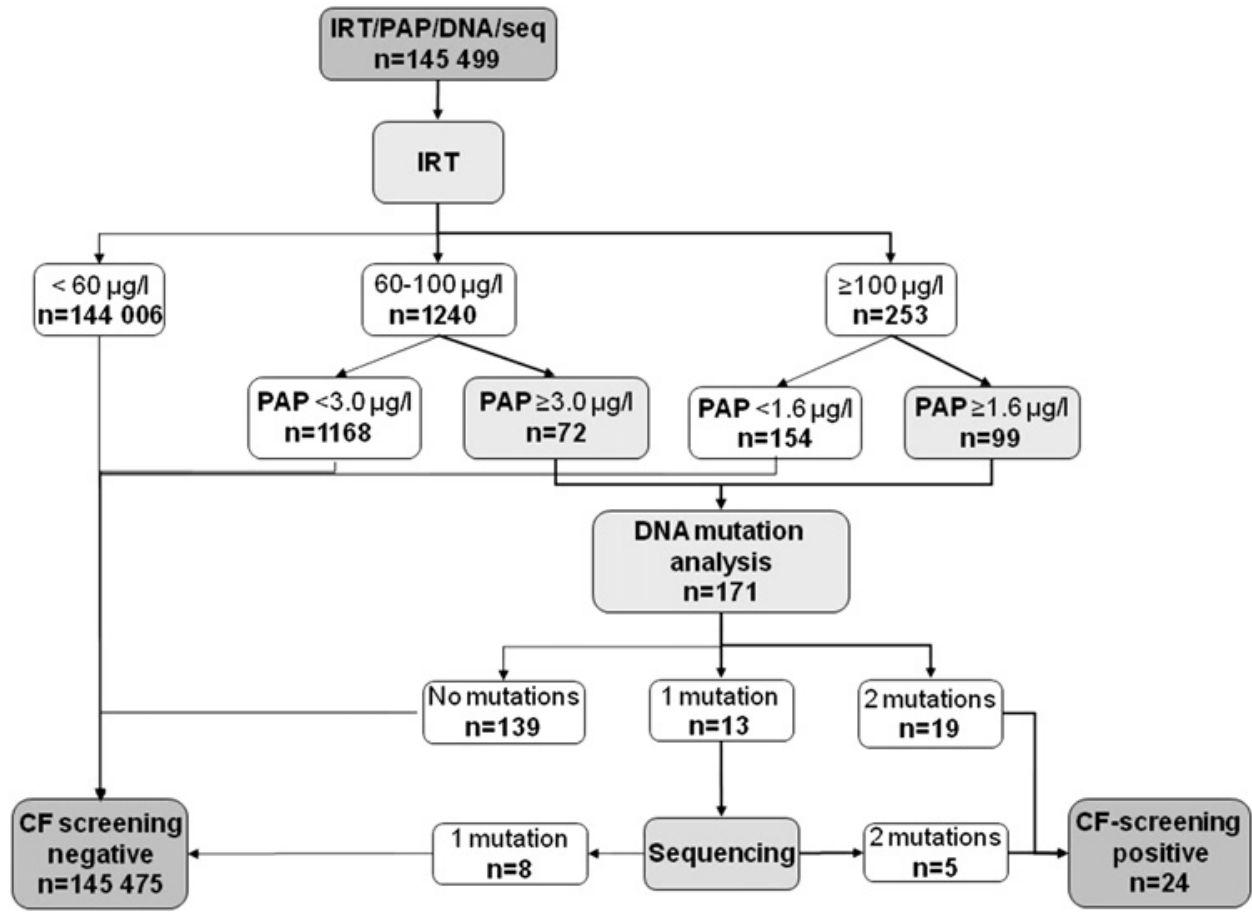

All infants with CF were diagnosed within 2 months of birth. In $90 \%$ of all newborns, the heel prick was taken within $144 \mathrm{~h}$ of birth (day 6). Median age at heel prick was $96 \mathrm{~h}$ (day 4) (IOR 96-120). Median time between heel prick and screening test result was 7 days for IRT/PAP (IOR 5-9) and 16 days for IRT/ DNA/sequencing (IOR 15-19). For IRT/PAP/DNA/sequencing the predicted time between heel prick and test result is 21 days. The period of uncertainty for parents from being informed about a positive heel prick result and confirmation or exclusion of the diagnosis was 4 days (IOR 3-7) in the first year of the study, and 1 day (IOR 1-7) in the second year, for both strategies.

\section{DPSU and the retrospective analysis}

Between January 2008 and April 2011 no false-negative results were reported.

Table 3 Immunoreactive trypsinogen and pancreatitis-associated protein concentrations, CFTR gene mutation analysis and sweat tests for all infants with an equivocal diagnosis

\begin{tabular}{llllll}
\hline & $\begin{array}{l}\text { IRT } \\
(\mu \mathbf{g} / \text { litre })\end{array}$ & $\begin{array}{l}\text { PAP } \\
(\mu \mathbf{g} / \text { litre })\end{array}$ & Mutation 1 & Mutation 2 & $\begin{array}{l}\text { Sweat test chloride } \\
(\mathbf{m m o l} / \text { litre })\end{array}$ \\
\hline 1 & 199 & 1.4 & E60X & R117H-7T & 36 \\
2 & 139 & 0.8 & 394delTT & R117H-7T/9T & 21 \\
3 & 123 & 0.6 & F508del & R117H-7T & 22 \\
4 & 89 & 1.4 & S1251N & R117H-7T & 29 \\
5 & 79 & 1.6 & F508del & R117H-7T & 26 \\
6 & 77 & 2.4 & R553X & R117H-7T & 22 \\
7 & 76 & 0.8 & F508del & R117H-7T & 34 \\
8 & 73 & 0.5 & F508del & R117H-7T & 25 \\
9 & 70 & 1.0 & F508del & R117H-7T & 22 \\
10 & 69 & 1.1 & F508del & R117H-7T & 33 \\
11 & 67 & 2.7 & F508del & R117H-7T & 17 \\
$12^{*}$ & 174 & 3.8 & F508del & L967S & 19 \\
$13^{*}$ & 84 & 3.2 & F508del & 01352H & 17 \\
\hline
\end{tabular}

Equivocal diagnosis=two CFTR gene mutations of which one has unclear clinical significance, and a normal or equivocal sweat test result.

*Second mutation detected by sequencing.

IRT, immunoreactive trypsinogen; PAP, pancreatitis-associated protein.
A retrospective analysis was performed in 74 cards. IRT and PAP concentrations declined with age of the heel prick card, therefore the results of the retrospective analysis could not be used to determine the sensitivity of this strategy. Our mutation panel detected two mutations in 66 cards, one mutation in seven cards and no mutations in one card. Eight cards were sequenced and after sequencing all cards contained two mutations. The 36mutation panel therefore had a sensitivity of $98.6 \%$ (95\% CI 91.6 to 99.9) for detection of one or two mutations.

\section{DISCUSSION}

As far as we know, our study is the first prospective study comparing two novel screening strategies in NBS for CF (IRT/ PAP and IRT/DNA/sequencing). The best test performance was found for IRT/DNA/sequencing. A post hoc analysis of a combination of both strategies (IRT/PAP/DNA/sequencing) resulted in a programme with a sensitivity similar to IRT/PAP but a higher specificity and PPV. This third strategy led to detection of considerably fewer carriers and fewer equivocal diagnoses than current screening strategies. This strategy has never been studied before.

All infants with CF were diagnosed within 2 months of birth, which is within the window of opportunity to create a better prognosis. ${ }^{14}$ Our study has some limitations that should be considered in the interpretation of the results. The currently most applied screening strategy for NBS for CF is the IRT/DNA

Table 4 Time to diagnosis

\begin{tabular}{|c|c|c|c|}
\hline Screening strategy & $\begin{array}{l}\text { IRT/ } \\
\text { PAP }\end{array}$ & $\begin{array}{l}\text { IRT/DNA/ } \\
\text { sequencing }\end{array}$ & $\begin{array}{l}\text { IRT/PAP/DNA/ } \\
\text { sequencing* }\end{array}$ \\
\hline $\begin{array}{l}\text { Median time between heel prick } \\
\text { and screening test result, days (IOR) }\end{array}$ & $7(5-9)$ & $16(15-19)$ & 21 \\
\hline \multicolumn{4}{|c|}{ Median time between screening test result and diagnosis, days (IQR) } \\
\hline First year of study & $4(3-7)$ & $4(3-7)$ & $4(3-7)$ \\
\hline Second year of study & $1(1-7)$ & $1(1-7)$ & $1(1-7)$ \\
\hline
\end{tabular}

*Predicted time period; this method was not tested in practice during the study. IRT, immunoreactive trypsinogen; PAP, pancreatitis-associated protein. 
strategy with referral of all infants with one or two mutations. In an ideal study design this strategy would have been used as the 'gold standard'. Using our study data an IRT/DNA programme would have had a sensitivity of $100 \%(95 \% \mathrm{CI}$ $88.2 \%$ to $100 \%$ ), a specificity of $99.954 \%$ (95\% CI $99.941 \%$ to $99.964 \%$ ) and a PPV of $26.4 \%$ (95\% CI $17.9 \%$ to $36.8 \%$ ), this may be investigated prospectively in a new study comparing those protocols. However, sequencing the CFTR gene in all infants with a single mutation and an equivocal sweat test is advised as the optimal diagnostic strategy in the current European consensus guidelines, ${ }^{11}$ and this most probably has a similar sensitivity to performing a sweat test in infants with a single CFTR mutation. Moreover, within our study it was possible to compare specificity and PPV with the 'gold standard' strategy; the IRT/DNA/sequencing strategy appears to have a considerably better specificity as well as PPV. We did not find a statistically significant difference between the IRT/PAP and IRT/DNA/ sequencing strategies; this may have been caused by the relatively small number of infants with CF in our screened population, which is also a limitation of our study.

The diagnosis was confirmed by the sweat test in 17 of the 20 infants. In all cases the diagnosis could be confirmed according to the international definition ${ }^{10} 11$ by a sweat test or a second DNA analysis and clinical symptoms and/or a sibling with CF. We used the DPSU to detect children with CF who were potentially missed by screening.

The power analysis showed that we needed 62 infants to determine the sensitivity reliably. In the study design a retrospective analysis of children known to have CF was planned to calculate the sensitivity, but this partly failed because IRT and PAP concentrations decreased over time (results not shown). The prevalence of CF in our study was 1:6062. In 2005 and 2006, the Dutch CF Registry registered a nationwide prevalence of 1:5000 comparable to the prevalence of 1:4750 published in $2005 .^{15}$ The reason for this difference may be that the prevalence of CF is declining as it is in the whole of Europe. ${ }^{16} 17$ Causes for this decline may be preconception and prenatal screening, parents deciding not to have any more children with NBS detecting carrier couples. Another cause may be a lower prevalence of CF in the southern part of the Netherlands where our study was performed. ${ }^{18} 19$ Our results for IRT/PAP are comparable to the findings of two previous studies. ${ }^{6} 7$ One previous study found a sensitivity of $100 \%$ for detection of CF with a specificity of $99.81 \%$ and a PPV of $9.4 \%{ }^{6}$ Another prospective study comparing IRT/PAP with IRT/DNA showed a sensitivity of $85.7 \%$, a specificity of $99.90 \%$ and a PPV of $12.2 \%$ for the IRT/ PAP strategy. The sensitivity in the last study appears low but this study used a slightly different protocol.

Internationally used screening programmes consisting of IRT, IRT/IRT or IRT/DNA (one or more mutations) show variable test performances. ${ }^{4}$ IRT/IRT programmes show a sensitivity between $80.2 \%$ and $96.8 \%$, with a specificity of $99.8 \%{ }^{20}{ }^{21}$ In DNA-based programmes (IRT/DNA, IRT/DNA/IRT, IRT/IRT/ DNA), the sensitivity varies depending on the mutation panel, the IRT cut-off level and the fail-safe procedures. Previous studies showed sensitivities of between $96.0 \%$ and $99.5 \%$ with specificities between $99.60 \%$ and $99.97 \% .^{22-24}$

IRT/PAP has advantages compared with DNA-based programmes. First, no carriers are detected. Although carrier detection is sometimes considered an advantage, this is not a universal opinion. ${ }^{25-28}$ The advantages of detection of traittrait couples and extended family screening do not counterbalance this disadvantage in our opinion. Second, no second heel prick is needed in contrast to IRT/IRT programmes. Disadvan- tages are the high number of false-positive test results, and a long period of uncertainty and parental stress due to the frequent failure of the sweat test.

The IRT/DNA/sequencing strategy had the best test performance in our study, but this strategy led to equivocal diagnoses and identified carriers. However, the number of referrals was considerably lower and the specificity and PPV higher than those of the most applied screening strategy, IRT/DNA. In contrast to current IRT/DNA-based programmes, the advantage of the IRT/ $\mathrm{DNA} /$ sequencing approach was that parents were not aroused by a positive screening test result when a single mutation was identified. ${ }^{29}$ The information leaflet about NBS for CF that the parents received at three occasions (during pregnancy, when registering the baby and immediately before the heel prick) mentioned that parents could ask for the DNA results, but very few parents did $(0.007 \%)$.

Eleven of the 13 infants with an equivocal diagnosis in the IRT/DNA/sequencing strategy had R117H-7T as a second mutation. Most of them had normal sweat test results (table 3 ), which means that they would probably have a normal or subnormal CFTR function. The Dutch CF Registry showed only 10 patients (1196 registered patients in 2008) with a R117H-7T mutation, and only four of them were diagnosed under the age of 18 years. Our findings confirm an earlier observed discrepancy in frequency of this mutation in screened populations and CF registries. This indicates that this mutation mostly acts as a non-disease-causing variant. ${ }^{30} 31$ Many experts on NBS for CF therefore advise exclusion of this mutation. ${ }^{31}$ If R117H-7T were to be excluded from the panel, only two infants with an equivocal diagnosis would have been identified with this strategy. With a IRT/DNA strategy these two infants would probably not be identified as having an equivocal diagnosis but only as carriers.

Because of the multi-ethnic Dutch population, infants with two rare mutations in the non-Caucasian population might be missed when using a DNA-based screening strategy. But in the retrospective analysis we identified only one patient that would not have been detected by the IRT/DNA/sequencing analysis. The IRT/PAP strategy reveals infants with CF because of high IRT and PAP levels, which makes this a more robust screening strategy when the screened population has ethnic differences.

In conclusion, all three studied screening strategies seem useful for NBS for CF, but the choice of which strategy to implement depends on the requirements of the test. Both strategies (IRT/PAP and IRT/DNA/sequencing) performed well, better than expected. Although there was no statistically significant difference, the IRT/DNA/sequencing strategy detected one infant that was missed by IRT/PAP. This strategy also leads to fewer referrals and therefore to a higher specificity and PPV than the current IRT/DNA strategy. IRT/ PAP may be the optimal choice if the use of DNA technology must be avoided. When identification of carriers or false-positive results are considered to be important disadvantages and the number of equivocal diagnoses should be minimised, IRT/PAP/ DNA/sequencing may be the best choice. The Dutch Ministry of Health decided to implement this last strategy in the Dutch NBS programme as of 1 May $2011 .^{32}$

\section{Author footnote}

CHOPIN Study Group J E Dankert-Roelse, MD, PhD, A M M Vernooij-van Langen, MD (Atrium Medical Centre); J G Loeber, PhD, L H Elvers (RIVM); R H Triepels, PhD (St Elisabeth Hospital); J J P Gille, PhD (VUmc); C P B Van der Ploeg, PhD (TNO Quality of Life); E Dompeling, MD, PhD (MUMC); G Pals, PhD (VU Medical Centre), S M van der Pal, PhD, M E van den Akker van Marle, PhD (TNO Quality of Life); V A M Gulmans PhD (NCFS, Dutch CF Foundation), M J W Oey-Spauwen, MD, Y H H M Wijnands, 
MD, L M Castricum, MD (RIVM); H G M Arets, MD, PhD, Professor C K van der Ent, MD, PhD (University Medical Centre Utrecht); Professor H A W M Tiddens, MD, PhD, Y B de Rijke, PhD (Erasmus Medical Centre Rotterdam); J B Yntema, MD, PhD (Radboud University Nijmegen Medical Centre).

Acknowledgements We thank the paediatric pulmonologists and CF nurses in the four participating $\mathrm{CF}$ centres for their care for the parents and their children: H G M Arets and Professor C K van der Ent, C de Kiviet (University Medical Centre Utrecht); Professor H A W M Tiddens, Y B de Rijke, A Kok and I Heeres (Erasmus Medical Centre Rotterdam); J B Yntema and J Sintnicolaas (Radboud University Nijmegen Medical Centre); Professor E Dompeling and D Holtslag (Maastricht University Medical Centre). We also thank Paul Verkerk from TNO Quality of Life for his contribution in preparation of the study protocol.

Funding ZonMw, the Dutch Organization for Health Research Development, financed the study at the request of the Dutch Health Council. ZonMw in no way influenced the data collection, analysis or interpretation of the results, and they did not comment about the writing of this article or the decision for submission.

Competing interests None.

Ethics approval The Medical Ethical Committee of the Atrium Medical Centre approved the performance of the CHOPIN study according to the Good Clinical Practice guidelines and privacy statements.

Contributors JD developed the study design and supported the analysis and interpretation of the results, and the writing. AV coordinated the study, analysed and interpreted the results and wrote the article. GL, BE and RT coordinated the performance of immunoreactive trypsinogen and pancreatitis-associated protein, and interpreted the results. HG coordinated and performed the DNA analysis and sequencing and interpreted the results. SR collected the data and referred all infants to the $C F$ centres. $C P$ and ED supported the analysis, interpretation and writing of the article. All authors participated in the study project group, worked on the study design and read the article extensively. All authors approved the final version to be published.

Provenance and peer review Not commissioned; externally peer reviewed

\section{REFERENCES}

1. Castellani C, Southern KW, Brownlee K, et al. European best practice guidelines for cystic fibrosis neonatal screening. J Cyst Fibros 2009;8:153-73.

2. Southern KW, Munck A, Pollitt R, et al. A survey of newborn screening for cystic fibrosis in Europe. J Cyst Fibros 2007;6:57-65.

3. Wilcken B. Newborn screening for cystic fibrosis: techniques and strategies. $J$ Inherit Metab Dis 2007;30:537-43.

4. Anon. Newborn screening for cystic fibrosis. MMWR 2004;53(RR-13):1-41.

5. Kai J, Ulph F, Cullinan T, et al. Communication of carrier status information following universal newborn screening for sickle cell disorders and cystic fibrosis: qualitative study of experience and practice. Health Technol Assess 2009;13:1-82, iii.

6. Sarles J, Berthezene P, Le Louarn $\mathbf{C}$, et al. Combining immunoreactive trypsinogen and pancreatitis-associated protein assays, a method of newborn screening for cystic fibrosis that avoids DNA analysis. J Pediatr 2005;147:302-5.

7. Sommerburg $\mathbf{0}$, Lindner $\mathrm{M}$, Muckenthaler $\mathrm{M}$, et al. Initial evaluation of a biochemical cystic fibrosis newborn screening by sequential analysis of immunoreactive trypsinogen and pancreatitis-associated protein (IRT/PAP) as a strategy that does not involve DNA testing in a northern European population. $J$ Inherit Metab Dis 2010;33(Suppl 2):S263-71.

8. Merelle ME, Scheffer $H$, De Jong $D$, et al. Extended gene analysis can increase specificity of neonatal screening for cystic fibrosis. Acta Paediatr 2006;95:1424-8.
9. Kharrazi M, Koepke R, Lessing $\mathbf{S}$, et al. Benefits of using an open-ended mutation testing platform during CF newborn screening: the California experience. Pediatr Pulmonol 2009:44(S32):Abstract 457, p373.

10. De Boeck K, Wilschanski M, Castellani $\mathrm{C}$, et al. Cystic fibrosis: terminology and diagnostic algorithms. Thorax 2006;61:627-35.

11. Mayell SJ, Munck A, Craig JV, et al. A European consensus for the evaluation and management of infants with an equivocal diagnosis following newborn screening for cystic fibrosis. J Cyst Fibros 2009;8:71-8.

12. Green A, Kirk J. Guidelines for the performance of the sweat test for the diagnosis of cystic fibrosis. Ann Clin Biochem 2007:44:25-34.

13. Newborn screening for cystic fibrosis: a paradigm for public health genetics policy development. Proceedings of a 1997 workshop. MMWR Recomm Rep 1997;46(RR16):1-24.

14. Sims EJ, Clark A, McCormick J, et al. Cystic fibrosis diagnosed after 2 months of age leads to worse outcomes and requires more therapy. Pediatrics 2007:119:19-28.

15. Slieker MG, Uiterwaal CS, Sinaasappel M, et al. Birth prevalence and survival in cystic fibrosis: a national cohort study in the Netherlands. Chest 2005:128:2309-15.

16. Hale JE, Parad RB, Comeau AM. Newborn screening showing decreasing incidence of cystic fibrosis. N Engl J Med 2008;358:973-4.

17. Scotet V, Assael BM, Dugueperoux I, et al. Time trends in birth incidence of cystic fibrosis in two European areas: data from newborn screening programs. J Pediatr 2008;152:25-32

18. Ten Kate LP. Cystic fibrosis in the Netherlands. Int J Epidemiol 1977;6:23-34.

19. de Vries HG, Collee JM, de Walle HE, et al. Prevalence of delta F508 cystic fibrosis carriers in The Netherlands: logistic regression on sex, age, region of residence and number of offspring. Hum Genet 1997;99:74-9.

20. Massie RJ, Olsen M, Glazner J, et al. Newborn screening for cystic fibrosis in Victoria: 10 years' experience (1989-1998). Med J Aust 2000:172:584-7.

21. Kloosterboer $\mathbf{M}$, Hoffman $\mathrm{G}$, Rock $\mathbf{M}$, et al. Clarification of laboratory and clinical variables that influence cystic fibrosis newborn screening with initial analysis of immunoreactive trypsinogen. Pediatrics 2009:123:e338-46.

22. Comeau AM, Parad RB, Dorkin HL, et al. Population-based newborn screening for genetic disorders when multiple mutation DNA testing is incorporated: a cystic fibrosis newborn screening model demonstrating increased sensitivity but more carrier detections. Pediatrics 2004;113:1573-81.

23. Munck A, Dhondt JL, Sahler C, et al. Implementation of the French nationwide cystic fibrosis newborn screening program. J Pediatr 2008;153:228-33, 233.e1.

24. Sontag MK, Wright D, Beebe J, et al. A new cystic fibrosis newborn screening algorithm: IRT/IRT1 upward arrow/DNA. J Pediatr 2009:155:618-22.

25. Liou TG, Rubenstein RC. Carrier screening, incidence of cystic fibrosis, and difficult decisions. JAMA 2009;302:2595-6.

26. Wheeler PG, Smith $\mathrm{R}$, Dorkin $\mathrm{H}$, et al. Genetic counseling after implementation of statewide cystic fibrosis newborn screening: two years' experience in one medical center. Genet Med 2001;3:411-15.

27. Lewis S, Curnow L, Ross M, et al. Parental attitudes to the identification of their infants as carriers of cystic fibrosis by newborn screening. J Paediatr Child Health 2006:42:533-7.

28. Lagoe E, Labella S, Arnold G, et al. Cystic fibrosis newborn screening: a pilot study to maximize carrier screening. Genet Test 2005;9:255-60.

29. Castellani C, Picci L, Scarpa M, et al. Cystic fibrosis carriers have higher neonatal immunoreactive trypsinogen values than non-carriers. Am J Med Genet $A$ 2005;135:142-4

30. Thauvin-Robinet C, Munck A, Huet F, et al. The very low penetrance of cystic fibrosis for the $\mathrm{R} 117 \mathrm{H}$ mutation: a reappraisal for genetic counselling and newborn screening. J Med Genet 2009;46:752-8.

31. Scotet V, Audrezet MP, Roussey M, et al. Immunoreactive trypsin/DNA newborn screening for cystic fibrosis: should the $\mathrm{R} 117 \mathrm{H}$ variant be included in CFTR mutation panels? Pediatrics 2006;118:e1523-9.

32. Dutch Health Council. Newborn Screening for Cystic Fibrosis. The Hague: Dutch Health Council, 2010. 